\title{
Remarks on some recent fixed point theorems
}

\author{
Hassen Aydi ${ }^{1}$, Erdal Karapınar ${ }^{2}$ and Bessem Samet ${ }^{3^{*}}$
}

\footnotetext{
* Correspondence: bessem. samet@gmail.com

${ }^{3}$ Department of Mathematics, King

Saud University, Riyadh, Saudi Arabia

Full list of author information is available at the end of the article
}

\begin{abstract}
The purpose of this article is to show that some recent fixed point theorems are particular results of previous existing theorems in the literature.

Mathematics Subject Classification 2000: 54H25; 47H10.

Keywords: fixed point, coupled fixed point, ordered set, metric space, cone metric space
\end{abstract}

\section{Introduction}

In this section, we recall some known results on fixed point theory.

We start with the well-known Banach contraction principle [1].

Theorem 1. Let $(X, d)$ be a complete metric space and let $F: X \rightarrow X$ be a mapping such that for each pair of points $x, y \in X$,

$$
d(F x, F y) \leq k d(x, y)
$$

where $k$ is a constant in $[0,1)$. Then $F$ has a unique fixed point.

In 2008, Dutta and Choudhury [2] obtained the following generalization of the Banach contraction principle.

Theorem 2. Let $(X, d)$ be a complete metric space and let $F: X \rightarrow X$ be a mapping such that for each pair of points $x, y \in X$,

$$
\psi(d(F x, F y)) \leq \psi(d(x, y))-\varphi(d(x, y))
$$

where $\psi, \phi:[0, \infty) \rightarrow[0, \infty)$ are continuous, non-decreasing and $\psi^{-1}(\{0\})=\phi^{1}(\{0\})=$ $\{0\}$. Then $F$ has a unique fixed.

Remark 3. Note that Theorem 2 remains true if $\phi$ satisfies only the following assumptions: $\phi$ is lower semi-continuous and $\phi^{-1}(\{0\})=\{0\}$ (see, for example, Abbas and Dorić [3] and Dorić [4]).

Using the above remark, we have also

Theorem 4. Let $(X, d)$ be a complete metric space and let $F: X \rightarrow X$ be a mapping such that for each pair of points $x, y \in X$,

$$
\psi(d(F x, F y)) \leq \psi(d(x, y))-\varphi(d(x, y))
$$

where $\psi:[0, \infty) \rightarrow[0, \infty)$ is continuous, non-decreasing, $\psi^{-1}(\{0\})=\{0\}$, and $\phi:[0, \infty)$ $\rightarrow[0, \infty)$ is lower semi-continuous and $\phi^{-1}(\{0\})=\{0\}$. Then $F$ has a unique fixed.

We have also an ordered version of Theorem 4 (see [3-5]).

Theorem 5. Let $(X, \preccurlyeq)$ be a partially ordered set and suppose that there is a metric $d$ on $X$ such that $(X, d)$ is a complete metric space. Let $F: X \rightarrow X$ be a continuous non-

\section{Springer}

(C) 2012 Aydi et al; licensee Springer. This is an Open Access article distributed under the terms of the Creative Commons Attribution License (http://creativecommons.org/licenses/by/2.0), which permits unrestricted use, distribution, and reproduction in any medium, provided the original work is properly cited. 
decreasing mapping such that

$$
\psi(d(F x, F y)) \leq \psi(d(x, y))-\varphi(d(x, y)),
$$

for all $x, y \in X$ with $x \leqslant y$, where $\psi:[0, \infty) \rightarrow[0, \infty)$ is continuous, non-decreasing, $\psi$ ${ }^{-1}(\{0\})=\{0\}$, and $\phi:[0, \infty) \rightarrow[0, \infty)$ is lower semi-continuous and $\phi^{-1}(\{0\})=\{0\}$. If there exists $x_{0} \in X$ such that $x_{0} \leqslant F x_{0}$, then $F$ has a fixed point.

The following result was obtained by Olaleru [6].

Theorem 6. Let $(X, d)$ be a cone metric space with a cone P having non-empty interior. Let $f, g: X \rightarrow X$ be mappings such that

$$
d(f x, f u) \leq \alpha_{1} d(f x, g x)+\alpha_{2} d(f u, g u)+\alpha_{3} d(f u, g x)+\alpha_{4} d(f x, g u)+\alpha_{5} d(g x, g u)
$$

for all $x, u \in X$, where $\alpha_{1}, \alpha_{2}, \alpha_{3}, \alpha_{4}, \alpha_{5} \in[0,1)$ and $\alpha_{1}+\alpha_{2}+\alpha_{3}+\alpha_{4}+\alpha_{5}<1$. Suppose that $f(X) \subseteq g(X)$ and $g(X)$ is a complete subspace of $X$. Then $f$ and $g$ have a coincidence point. Moreover, if $f$ and $g$ are weakly compatible, then $f$ and $g$ have a unique common fixed point.

The purpose of this article is to show that some recent fixed point theorems are particular cases of the above mentioned results. This article can be considered as a continuation of the recent work of Haghi et al. [7].

\section{Main results}

Beiranvand et al. [8] introduced a new class of mappings $T: X \rightarrow X$ as follows.

Definition 7. The mapping $T: X \rightarrow X$ is said to be sequentially convergent, if the sequence $\left\{y_{n}\right\}$ in $X$ is convergent whenever $\left\{T y_{n}\right\}$ is convergent.

In the same article, the authors established the following result.

Theorem 8. Let $(X, d)$ be a complete metric space and $T, f: X \rightarrow X$ be two mappings satisfying

$$
d(T f x, T f y) \leq k d(T x, T y)),
$$

for all $x, y \in X$, where $k$ is a constant in $[0,1)$ and $T$ is continuous, injective and sequentially convergent. Then $f$ has a unique fixed point.

Theorem 8 has attracted the attention of many authors, see, for example, [9-15], where extensions and generalizations of Theorem 8 were considered.

We shall prove the following result.

Theorem 9. Theorem 1 and Theorem 8 are equivalent.

Proof. Clearly, if $T$ is the identity mapping, Theorem 8 reduces to Theorem 1 . Now, we shall prove that Theorem 8 can be deduced for the Banach contraction principle. Define the mapping $\delta: X \times X \rightarrow[0, \infty)$ by

$$
\delta(x, y)=d(T x, T y), \quad x, y \in X .
$$

For all $x, y, z \in X$, we have $\delta(x, y)=\delta(y, x), \delta(x, y) \leq \delta(x, y)+\delta(y, z)$ and

$$
\delta(x, y)=0 \Leftrightarrow d(T x, T y)=0 \Leftrightarrow T x=T y \Leftrightarrow x=y \text { (since } T \text { is injective). }
$$

Then $\delta$ is a metric on $X$. Moreover, $(X, \delta)$ is a complete metric space. Indeed, let $\left\{x_{n}\right\}$ be a Cauchy sequence in $(X, \delta)$. From the definition of $\delta$, this implies that $\left\{T x_{n}\right\}$ is a Cauchy sequence in $(X, d)$. Since $(X, d)$ is complete, there exists $y \in X$ such that $d(T$ $\left.x_{n}, y\right) \rightarrow 0$ as $n \rightarrow \infty$. But $T$ is sequentially convergent, then there exists $x \in X$, such 
that $d\left(x_{w}, x\right) \rightarrow 0$ as $n \rightarrow \infty$. Since $T$ is continuous, this implies that $d\left(T x_{w}, T x\right) \rightarrow 0$ as $n \rightarrow \infty$, that is, $\delta\left(x_{w}, x\right) \rightarrow 0$ as $n \rightarrow \infty$. This proves that $(X, \delta)$ is complete. Now, condition (4) reduces to

$$
\delta(f x, f y) \leq k \delta(x, y)
$$

for all $x, y \in X$. Thus Theorem 8 follows immediately from the Banach contraction principle (Theorem 1).

Recently, Eslamian and Abkar [16] etablished the following result.

Theorem 10. Let $(X, d)$ be a complete metric space and $f: X \rightarrow X$ be such that

$$
\psi(d(f x, f y)) \leq \alpha(d(x, y))-\beta(d(x, y)),
$$

for all $x, y \in X$, where $\psi, \alpha, \beta:[0, \infty) \rightarrow[0, \infty)$ are such that $\psi$ is continuous and non-decreasing, $\alpha$ is continuous, $\beta$ is lower semi-continuous,

$$
\begin{aligned}
& \psi(t)=0 \text { if and only if } t=0, \alpha(0)=\beta(0)=0, \\
& \text { and } \psi(t)-\alpha(t)+\beta(t)>0 \text { for all } t>0 .
\end{aligned}
$$

Then $f$ has a unique fixed point.

We shall prove the following result.

Theorem 11. Theorem 10 and Theorem 4 are equivalent.

Proof. Taking $\alpha=\psi$ in Theorem 10, we obtain immediately Theorem 4. Now, we shall prove that Theorem 10 can be deduced from Theorem 4 . Indeed, let $f: X \rightarrow X$ be a mapping satisfying (5) with $\psi, \alpha, \beta:[0, \infty) \rightarrow[0, \infty)$ satisfy conditions (6) and (7). From (5), for all $x, y \in X$, we have

$$
\begin{aligned}
\psi(d(f x, f y)) & \leq \alpha(d(x, y))-\beta(d(x, y)) \\
& =\psi(d(x, y))-[\beta(d(x, y))-\alpha(d(x, y))+\psi(d(x, y))]
\end{aligned}
$$

Define $\theta:[0, \infty) \rightarrow[0, \infty)$ by

$$
\theta(t)=\beta(t)-\alpha(t)+\psi(t), t \geq 0 .
$$

Then, we have

$$
\psi(d(f x, f y)) \leq \psi(d(x, y))-\theta(d(x, y)),
$$

for all $x, y \in X$. Clearly, from (6) and (7), $\theta$ is lower semi-continuous and $\theta^{1}(\{0\})=$ $\{0\}$. Now, Theorem 10 follows immediately from Theorem 4 . $\square$

Binayak et al. [17] extended Theorem 10 to the ordered case.

Theorem 12. Let $(X, \preccurlyeq)$ be a partially ordered set and suppose that there is a metric $d$ on $X$ such that $(X, d)$ is a complete metric space. Let $f: X \rightarrow X$ be a continuous nondecreasing mapping such that

$$
\psi(d(f x, f y)) \leq \alpha(d(x, y))-\beta(d(x, y)),
$$

for all $x, y \in X$ with $x \leqslant y$, where $\psi, \alpha, \beta:[0, \infty) \rightarrow[0, \infty)$ are such that $\psi$ is continuous and non-decreasing, $\alpha$ is continuous, $\beta$ is lower semi-continuous,

$$
\psi(t)=0 \text { if and only if } t=0, \alpha(0)=\beta(0)=0,
$$




$$
\text { and } \psi(t)-\alpha(t)+\beta(t)>0 \text { for all } t>0 \text {. }
$$

If there exists $x_{0} \in X$ such that $x_{0} \leqslant f x_{0}$, then $f$ has a fixed point.

Following similar arguments as in the proof of Theorem 11, we obtain

Theorem 13. Theorem 5 and Theorem 12 are equivalent.

Abbas et al. [18] introduced the concept of $w$-compatibility for a pair of mappings $F$ : $X \times X \rightarrow X$ and $g: X \rightarrow X$.

Definition 14. The mappings $F: X \times X \rightarrow X$ and $g: X \rightarrow X$ are called $w$-compatible if $g(F(x, y))=F(g x, g y)$ whenever $g x=F(x, y)$ and $g y=F(y, x)$.

In the same article, the authors established the following result.

Theorem 15. Let $(X, d)$ be a cone metric space with a cone $P$ having non-empty interior, $F: X \times X \rightarrow X$ and $g: X \rightarrow X$ be mappings satisfying

$$
\begin{aligned}
& d(F(x, y), F(u, v)) \leq a_{1} d(g x, g u)+a_{2} d(F(x, y), g x)+a_{3} d(g y, g u) \\
& +a_{4} d(F(u, v), g u)+\alpha_{5} d(F(x, y), g u)+a_{6} d(F(u, v), g x),
\end{aligned}
$$

for all $x, y, u, v \in X$, where $a_{i} i=1,2, \ldots, 6$ are nonnegative real numbers such that $\sum_{i=1}^{6} a_{i}<1$. If $F(X \times X) \subseteq g(X)$ and $g(X)$ is complete subset of $X$, then $F$ and $g$ have a coupled coincidence point in $X$, that is, there exists $(x, y) \in X \times X$ such that $g x=F(x$, $y)$ and $g y=F(y, x)$. Moreover, if $F$ and $g$ are w-compatible, then there exists a unique $u$ $\in X$ such that $u=g u=F(u, u)$.

We shall prove the following result.

Theorem 16. Theorem 6 and Theorem 15 are equivalent.

Proof. (i) Theorem $15 \Rightarrow$ Theorem 6. Let $f, g: X \rightarrow X$ be mappings satisfying the hypotheses of Theorem 6 . Define the mapping $F: X \times X \rightarrow X$ by

$$
F(x, y)=f x, \quad x, y \in X .
$$

From (3), we get

$$
\begin{aligned}
d(F(x, y), F(u, v))< & \alpha_{1} d(F(x, y), g x)+\alpha_{2} d(F(u, v), g u)+\alpha_{3} d(F(u, v), g x)+\alpha_{4} d(F(x, y), g u) \\
& +\alpha_{5} d(g x, g u),
\end{aligned}
$$

for all $x, y, u, v \in X$. Then condition (8) is satisfied with $\left(a_{1}, a_{2}, a_{3}, a_{4}, a_{5}, a_{6}\right)=\left(\alpha_{5}\right.$, $\left.\alpha_{1}, 0, \alpha_{2}, \alpha_{4}, \alpha_{3}\right)$. On the other hand, from the definition of $F$, we have $F(X \times X)=f(X)$ $\subseteq g(X)$. Also, $g(X)$ is a complete subspace of $(X, d)$. Now, applying Theorem 15, we obtain that $F$ and $g$ have a coupled coincidence point in $X$, that is, there exists $(x, y) X$ $\times X$ such that $g x=F(x, y)$ and $g y=F(y, x)$. From the definition of $F$, this implies that $g x=f x$, that is, $x$ is a coincidence point of $f$ and $g$. Suppose now that $f$ and $g$ are weakly compatible. Let $x, y \in X$ such that $g x=F(x, y)$. This implies that $g x=f x$. Since $f$ and $g$ are weakly compatible, we get $f g x=g f x$, that is, $F(g x, g y)=g(F(x, y))$. This implies that $F$ and $g$ are $w$-compatible. From Theorem 15, there exists a unique $u \in X$ such that $u$ $=g u=F(u, u)$, that is, there exists a unique $u L X$ such that $u=g u=f u$. Then $f$ and $g$ have a unique common fixed point. Thus we proved Theorem 6 .

(ii) Theorem $6 \Rightarrow$ Theorem 15 .

Let $F: X \times X \rightarrow X$ and $g: X \rightarrow X$ be mappings satisfying the hypotheses of Theorem 15. Define the mapping $f: X \rightarrow X$ by 


$$
f x=F(x, x), x \in X .
$$

From (8), we have

$$
d(f x, f u) \leq \alpha_{1} d(f x, g x)+\alpha_{2} d(f u, g u)+\alpha_{3} d(f u, g x)+\alpha_{4} d(f x, g u)+\alpha_{5} d(g x, g u),
$$

for all $x, u \in X$, where $\left(\alpha_{1}, \alpha_{2}, \alpha_{3}, \alpha_{4}, \alpha_{5}\right)=\left(a_{2}, a_{4}, a_{6}, a_{5}, a_{1}+a_{3}\right)$. Then condition (3) of Theorem 6 is satisfied. On the other hand, we have $f(X) \subseteq F(X \times X) \subseteq g(X)$ and $g(X)$ is a complete subspace of $(X, d)$. Applying Theorem 6 , we obtain that there exists $x \in X$ (a coincidence point) such that $f x=g x$, that is, $F(x, x)=g x$. Moreover, if $F$ and $g$ are $w$-compatible, then $f$ and $g$ are weakly compatible. Applying again Theorem 6 , we obtain that $f$ and $g$ have a unique common fixed point, that is, there exists a unique $u$ $\in X$ such that $u=g u=f u=F(u, u)$. Thus we proved Theorem 15 .

\section{Acknowledgements}

The authors thank the referees for their helpful remarks and suggestions which improved the final presentation of this article.

\section{Author details}

${ }^{1}$ Institut Supérieur d'Informatique et des Technologies de Communication de Hammam Sousse, Université de Sousse, Route GP1-4011, Hammam Sousse, Tunisie ²Department of Mathematics, Atılım University, Incek, 06836, Ankara, Turkey ${ }^{3}$ Department of Mathematics, King Saud University, Riyadh, Saudi Arabia

\section{Authors' contributions}

All authors contributed equally and significantly in writing this article. All authors read and approved the final manuscript.

\section{Competing interests}

The authors declare that they have no competing interests.

\section{Received: 1 February 2012 Accepted: 8 May 2012 Published: 8 May 2012}

\section{References}

1. Banach, S: Sur les opérations dans les ensembles abstraits et leur application aux équations intégrales. Fund Math. 3, 133-181 (1922)

2. Dutta, PN, Choudhury, BS: A generalization of contraction principle in metric spaces. Fixed Point Theory Appl 2008, 8 (2008). (Article ID 406368)

3. Abbas, M, Dorić, D: Common fixed point theorem for four mappings satisfying generalized weak contractive condition. Filomat. 24(2):1-10 (2010). doi:10.2298/FIL1002001A

4. Dorić, D: Common fixed point for generalized $(\psi, \phi)$-weak contractions. Appl Math Lett. 22, 1896-1900 (2009). doi:10.1016/j.aml.2009.08.001

5. Harjani, J, Sadarangani, K: Generalized contractions in partially ordered metric spaces and applications to ordinary differential equations. Nonlinear Anal. 72, 1188-1197 (2010). doi:10.1016/j.na.2009.08.003

6. Olaleru, JO: Some generalizations of fixed point theorems in cone metric spaces. Fixed Point Theory Appl 2009, 10 (2009). (Article ID 6579140)

7. Haghi, RH, Rezapour, Sh, Shahzad, N: Some fixed point generalizations are not real generalizations. Nonlinear Anal. 74 1799-1803 (2011). doi:10.1016/j.na.2010.10.052

8. Beiranvand, A, Moradi, S, Omid, M, Pazandeh, H: Two fixed point theorems for special mappings. arxiv:0903.1504v1 math FA. (2009)

9. Satisfying a contractive condition depended on an another function: Lobachevskii J Math. 30(4):289-291 (2009) doi:10.1134/S1995080209040076

10. Chi, KP, Thuy, HT: A fixed point theorem in 2-metric spaces for a class of maps that satisfy a contractive condition dependent on an another function. Lobachevskii J Math. 31(4):338-346 (2010). doi:10.1134/\$1995080210040050

11. Luong, NV, Thuan, NX, Hai, TT: Coupled fixed point theorems in partially ordered metric spaces depended on another function. Bull Math Anal Appl. 3(3):129-140 (2011)

12. Moradi, S, Alimmohammadi, D: New extensions of Kannan fixed-point theorem on complete metric and generalized metric spaces. Int J Math Anal. 5(47):2313-2320 (2011)

13. Moradi, S, Omid, M: A fixed-point theorem for integral type inequality depending on another function. Int J Math Anal. 4(29-32):1491-1499 (2010)

14. Morales, JR, Rojas, E: Cone metric spaces and fixed point theorems of T-Kannan contractive mappings. Int J Math Anal. 4(4):175-184 (2010)

15. Sumitra, R, Uthariaraj, VR, Hemavathy, R: Common fixed point theorem for $T$-Hardy-Rogers contraction mapping in a cone metric space. Int Math Forum. 5(30):1495-1506 (2010)

16. Eslamian, M, Abkar, A: A fixed point theorems for generalized weakly contractive mappings in complete metric space. Ital J Pure Appl Math. (in press) 
17. Choudhury, BS, Kundu, A: $(\psi, a, \beta)$-weak contractions in partially ordered metric spaces. Appl Math Lett. 25, 6-10 (2012). doi:10.1016/j.aml.2011.06.028

18. Abbas, M, Ali Khan, M, Radenović, S: Common coupled fixed point theorems in cone metric spaces for w-compatible mappings. Appl Math Comput. 217(1):195-202 (2010). doi:10.1016/j.amc.2010.05.042

doi:10.1186/1687-1812-2012-76

Cite this article as: Aydi et al: Remarks on some recent fixed point theorems. Fixed Point Theory and Applications $20122012: 76$.

Submit your manuscript to a SpringerOpen ${ }^{\odot}$ journal and benefit from:

- Convenient online submission

- Rigorous peer review

- Immediate publication on acceptance

- Open access: articles freely available online

- High visibility within the field

- Retaining the copyright to your article

Submit your next manuscript at $\gg$ springeropen.com 